\title{
The Tricky Terrain of Global University Partnerships
}

\author{
James Soto Antony and Tara Nicola
}

\section{Introduction}

Higher education in the USA, for the most part, is an industry in which individual institutions pride themselves on their autonomy, often behaving as independent actors among a broader population of over 4200 institutions. Even within state systems, which the casual observer would assume enjoy deep coordination among constituent institutions, there is fierce independence and competition.

Take, for example, the University of California (UC) system, which is composed of ten institutions (some widely known campuses include UCLA, UC Berkeley, UC San Diego, and UC San Francisco, for example). One might assume that, because each of these ten campuses belongs to the same state system, there exists considerable cooperation and coordination, even consensus, among the campuses. Yet all ten of these campuses are in regular competition with one another for resources, for the best and brightest faculty and students, and for influence both within the state and across the globe. Where degrees of cooperation and collaboration exist, they do so on the margins in the name of broadly defined system goals that allow all ten campuses to enjoy a set of minimum standards and expectations for policy, for the provision of basic administrative functions (for example, a common application system that the campuses with undergraduate populations use to gather and manage applications), or for overall systemwide priority and direction-setting. But, these ten institutions are, and will always remain, in competition with one another. This is just a cursory description of what happens in one state system. When considering colleges and universities that are truly independent of one another, that are not within the same state system, the competition among these campuses is even fiercer [1-3].

J. S. Antony $(\bowtie) \cdot$ T. Nicola

Harvard University, 13 Appian Way, Cambridge,

MA 02138, USA

e-mail: jantony@ucsd.edu

T. Nicola

e-mail: tara_nicola@gse.harvard.edu
If the model of American higher education, even within what are supposed to be highly coordinated state systems, reflects an attitude of competition and little collaboration, then one might wonder why colleges and universities in the USA increasingly seek collaborations and partnerships with institutions in other nations. Why would the University of Washington actively pursue a partnership with Tsinghua University in China, but find a partnership with MIT, UC Berkeley, or Harvard so challenging to consider, let alone execute? Why would New York University (NYU) desire to open satellite campuses in Abu Dhabi and Shanghai, before opening a campus in Los Angeles, San Francisco, or Seattle? Why would Yale University partner with the National University of Singapore (NUS) to create Yale-NUS, rather than dramatically increase the size of its current campus, or create a second campus on US soil?

We believe the answer to these questions lies in what US-based institutions perceive to be the primary benefits of global partnerships: to increase revenues, to bring about an expansion of institutional reputation and brand, to make the learning of their students and the impact of their scholarship more global, and to gain access to scholarly opportunities not otherwise available. US-based institutions seek to gain a foothold in what they perceive to be emerging markets that contain circumstances that do not exist domestically and that hold promise for dramatically improving their stature and resources. Of course, there are also a host of challenges, and we will discuss these, too.

In this chapter, we will briefly delve into the history of partnerships and collaborations between US-based institutions and global institutions. We will then present a taxonomy that explains the basic types of collaborations and partnerships that exist, describing their elements, what they have in common, and the ways in which they are distinct. After doing so, we will discuss the ways in which US-based institutions that have entered into global collaborations and partnerships have both benefitted from, and been challenged by, these arrangements. 
Through much of this chapter, we use US-based institutions, and descriptions of their global collaborations and partnerships, as the point of reference. We do this not because we believe that the USA is an exemplar for the world-after all, our extensive global travels as scholars convince us that other nations have much to teach the USA, and that institutions of higher education in the USA would be well served to pay attention to innovations happening in other nations. Rather, we begin our discussion with the USA for two reasons. The first is that many institutions outside of the USA actively seek to enter into partnerships with US-based institutions, especially those with global brand names. So, understanding lessons learned from the experiences of several of these US-global partner arrangements makes sense. Second, the majority of extant international collaborations or partnerships involve a US institution with an institution from another nation.

That said, after situating our discussion within the US example, describing the forms these collaborations and partnerships can take and their associated challenges and benefits, we will widen the discussion with an examination of the broader lessons learned. Specifically, we will discuss the implications of global collaborations and partnerships not just for US-based institutions, but also for those from other nations that might be considering entering into collaborations or partnerships with any other global partner.

\section{History of Global Partnerships}

The history of global partnerships between higher education institutions can be traced as far back as the seventeenth century. During colonial times, establishing a branch campus to promote the cultural assimilation of settlers was commonplace. The British created colleges in Africa and Australia [4] while the Dutch and French formed schools in Asia [5]. The Roman Catholic Church during this period was also engaged in globalization efforts, encouraged by the Spanish monarchy to establish universities in Latin and South America as well as the Philippines [5]. Colonial powers essentially exported their educational institutions abroad, imposing the institutional model, curriculum, and values of the dominant university in the metropole on the colonial institution [6]. In fact, the export model underlied the foundation of the nine colonial colleges in the US, institutions like Harvard University and the College of William and Mary modeled after their counterparts in Oxford and Cambridge.

During the eighteenth and nineteenth centuries, there was a focus on the expansion and development of US higher education domestically. It was not until the late-1800s that the newly formed US model of higher education, an amalgam of the English liberal arts college and German research university, was first exported abroad [5]. On account of Protestant missionaries, a number of American institutions were formed overseas. For example, missionaries established the co-educational Christian College of China in 1888 [7], the forerunner to today's Sun Yat-sen University and Lingnan University, as well as the Lebanese American University and the American University of Beirut [8]. These international colleges were not actual partnerships between US universities and those abroad but rather autonomous institutions that embraced a US style of education.

\subsection{Internationalization of US Higher Education}

US institutions did not formally engage in global partnerships until the early 1900s. The early partnerships were limited in scope, focused on short-term study. The University of Delaware was the first US institution to sponsor a formal study abroad program for undergraduates, establishing a partnership with the Sorbonne in 1923. Initially, proposed by Prof. Raymond W. Kirkbridge at Delaware, a World War I veteran who understood the importance of promoting cross-cultural understanding, the Delaware Foreign Study Plan, as it was called, eventually expanded to include partnerships with institutions in Switzerland and Germany [9].

By 1948, the Junior Year Abroad (JYA) program had sent over 900 students from the University of Delaware and other Northeast colleges to partner institutions abroad [9]. Due to the popularity of Delaware's Foreign Study Plan, Smith College established in 1925 its own JYA programs in Paris, Madrid, and Florence [10]. Paris was a particularly attractive destination for these programs given interest among the French in cultivating a positive relationship with Americans, as well as the country's long-standing interest in disseminating its language and culture beyond its national borders [11].

\subsection{US Institutions Abroad: 1900s-Present}

Sanguine French-American relations laid the foundation for the first international branch campus. As defined by the Observatory on Borderless Higher Education, an international branch campus can be broadly defined as "an entity that is owned, at least in part, by a foreign education provider; operated in the name of the foreign education provider; and provides access to an entire academic program, substantially on site, leading to a degree awarded by the foreign education provider" [12]. In 1921, the Paris Ateliers of the New York School of Fine and Applied Art was founded as a branch of what is today Parsons the New School of Design. Offering courses in scenography, 
decorative arts, and costume design [13], the Paris school was established to enrich the learning of American students [8]. The campus remains in operation today as the Paris College of Art, although no longer affiliated with the New School [14].

Despite the success of the Parsons Paris campus, other US institutions were slow to develop overseas footprints. It was not until after World War II that there was growing interest in establishing international partnerships. Nearly, 30 years after the founding of Parsons Paris, the Johns Hopkins University School of Advanced International Studies (SAIS) set up a center in Bologna, Italy. Founded in 1955, SAIS was the first American graduate school located in Europe and remains today a leader in the fields of international relations, economics, and social policy. A number of other institutions subsequently opened branch campuses in the 1970s, Boston University, Webster University, the American Intercontinental University, Alliant International University, and the University of La Verne forming campuses in Belgium, Switzerland, the UK, Mexico, and Greece, respectively [15].

By the 1980s, there was a growing interest among US institutions in exploring other types of international partnerships, including bilateral linkage programs such as joint research laboratories, concurrent and joint degree programs ("twinning" arrangements), and franchising [16]. During this same time, US colleges and universities also started to extend their influence beyond Europe to Asia, specifically Japan. A 1986 initiative spearheaded by the USA-Japan Committee for Promoting Trade Expansion ultimately led 30 US institutions to launch branch campuses in Japan as well as bilateral linkage programs and other educational partnerships with Japanese universities [16].

\subsection{Global Partnerships in the Twenty-First Century}

It was not until the mid-1990s, however, that there was an explosion in the number of US institutions seeking international partnerships, with over 35 overseas branch campuses opening just between 1995 and 2000. By 2015, an additional 179 campuses were established. During this time, regional education hubs also began to form, or regions specifically designed to house branch campuses from multiple institutions [17]. For example, the United Arab Emirates (UAE) has the Dubai International Academic City with branch campuses of the Rochester Institute of Technology, St. Joseph University, and Michigan State University, among others.

Today, there are approximately 250 international branch campuses across 70 countries, serving over 180,000 students; 77 of those campuses, or nearly a third, are affiliated with US institutions [18]. The majority of US branch campuses are located in Asia and the Middle East. In addition, although there is no official count of the number of bilateral linkage programs in existence, it is estimated there are hundreds, if not thousands, in operation [19]. Evidence suggests that the number of cross-border higher education partnerships will only continue to grow in the coming years [20].

\section{A Taxonomy of Global Partnerships}

Global partnerships can take many different forms. Our analysis of the numerous examples of existing partnerships leads us to conclude that, despite these differences, all partnerships can be organized into a taxonomy. This taxonomy, which is depicted in Table 1, captures the levels of resource co-dependence and autonomy the partners exercise or maintain, and also describes the nature of programmatic goals. As can be seen in Table 1, there are notable examples illustrating the final three categories. The first twoone-on-one collaborations, and program or center collaborations - are ubiquitous on every university campus around the world, and do not require specific examples for illustration. Inter-program simultaneous matriculation, though theoretically possible, is rare.

\subsection{One-on-One Collaborations and Exchanges}

One-on-one collaborations and exchanges are typically informal arrangements between two faculty members located at institutions in different countries. These partnerships may revolve around a particular work product, such as a co-written scholarly piece or coordinated efforts centered on data collection. Sometimes these partnerships might include exchanges where one faculty member visits another's seminars or classes, or even gives a talk and interacts with colleagues and students at the other partner's campus. What might begin informally can, with success over time, lead to slightly more formal arrangements in which the two faculty members begin to co-write grants, invoking their home institutions to think through a structure for the sharing of resources. This kind of evolution might also bring together more colleagues from each partner's home institution or even students. What is important to understand is that the pattern typically begins rather informally-centered upon shared intellectual interests - and, with success over time, begins to crystalize and adopt more formal structures.

It should be noted that, although these kinds of one-on-one collaborations and exchanges typically occur among faculty, examples of students following a similar pattern of initial collaboration and exchange exist. Regardless, success over time often can move these nascent one-on-one collaborations and exchanges toward the next stage: program/center collaborations and concurrent degrees. 
Table 1 Partnership taxonomy

Type
One-on-one collaborations
and exchanges

Program or center collaborations and inter-institution simultaneous matriculation
Description

Typically, these are informal

arrangements between two faculty members located at institutions in different countries. Student collaboration and exchanges also exist, although they are less common

Formal arrangements between academic programs or research centers, these collaborations involve the co-sharing of resources and an effort to articulate mutual goals. They can revolve strictly around bringing scholars together to conduct work or they can support students pursuing degrees concurrently at their home institution and the partner institution. Rules or policies that allow students to simultaneously or concurrently pursue degrees at each institution can be instituted, but each institution retains full authority over their own degree programs
Joint or dual degree programs

Joint degree programs allow students to work across the boundaries of two institutions, earning a co-branded singular degree that is conferred by both institutions. Joint programs involve much deeper coordination between the collaborating universities and more complex academic and financial agreements

\begin{tabular}{|l|l|}
\hline Satellite or branch & Universities choose to partner with
\end{tabular} campuses governments to set up US branches of their own brand abroad. For the most part, universities set up their own campus and maintain virtually all authority over the hiring of faculty, admissions, program design and standards, and the granting of degrees

Co-branded institutions Institutions partner with a local institution to develop a co-branded university, combining two academic cultures into one. This is tricky to achieve, and few co-branded institutions exist as a result

Examples

The list of these kinds of one-on-one arrangements would be exhaustive, because they are arranged mostly through personal connections. Every institution enjoys hundreds

The list of center collaborations is exhaustive, as this practice is ubiquitous. Inter-institution simultaneous matriculation is possible in theory, but rare in practice as these are not formal arrangements (i.e., they require an individual student to reach out to each institution to make this arrangement occur)

Appalachian State UniversityUniversidad de las Américas Puebla; National University of SingaporeSciences Po; University of Arizona

—Nisantasi University

New York University, Abu Dhabi

Duke Kunshan University;

Yale-NUS College

\subsection{Program or Center Collaborations and Inter-institution Simultaneous Matriculation}

Collaborations or partnerships between academic programs or research centers can revolve strictly around research, bringing scholars together to work on problems of shared interest. They can also bring students together to exchange ideas, take a course together, co-study either virtually or in person, and sometimes even pursue degrees concurrently at their home institution and the partner institution. Often, these kinds of partnerships and collaborations evolve from successful initial one-on-one exchanges. However, sometimes these grow whole-cloth from perceived shared interests absent any initial proof-of-concept experiences.

By definition, these kinds of partnerships and collaborations are more formal, involving a co-sharing of resources and an effort to articulate mutual goals. As a result, there is 
greater co-dependency. Yet, because these collaborations and partnerships are limited or focused in nature, they rarely force the two home universities to engage in complex financial exchanges. Often, each home institution retains complete fiscal autonomy and merely makes in-kind contributions, such as the provision of space or faculty time.

Theoretically, students might wish to pursue, simultaneously, degrees from different institutions. This should not be confused with intra-institution concurrent degrees, wherein a student at one university pursues two different degree programs (such as a law degree and an MBA, at the same time). Inter-institution simultaneous matriculation is rare. This arrangement would enable a student to pursue two degrees, from two different institutions, simultaneously. It is rare because most institutions have policies that do not allow a student to matriculate in two degree programs at two different institutions. Even if this arrangement is possible, students would not cross-register at the two institutions, and faculty from the two institutions would retain their affiliations with, and be paid by, their home institutions. Basically, to enable simultaneous matriculation, a student would have to take it upon themselves to make the arrangement occur, and each institution would have to institute policies that allow the student to do so. Academic requirements would not be merged or reconciled, and students would need to fulfill the requirements of their home institutions. These kinds of arrangements differ from organized, joint, or dual degree programs (which we will discuss next), wherein institutions have collaborated on combining aspects of their programs, allowing students to earn a separate degree from each of the two institutions while fulfilling all the requirements set by each institution (and, typically, paying separate tuition to each university).

\subsection{Joint or Dual Degree Programs}

As a further-evolved form of partnerships, joint degree programs are increasingly being developed around the world. These arrangements allow students to work across the boundaries of two institutions, earning a co-branded singular degree that is conferred by both institutions. Unlike concurrent degree programs, joint programs involve much deeper coordination between the collaborating institutions (and their degree-granting authorities) and more complex academic and financial agreements. Faculty commitment of time is still often structured in such a way as to allow each institution to retain oversight, as well as appointment and promotion authority, over their own faculty membersco-appointments of faculty at both institutions are rare but, when they occur, are typically honorific in nature. Compensation for the portion of faculty time dedicated to the joint program is often paid from resources generated by the joint program itself.

Because of the ways in which these joint programs are structured, they blend a higher level of co-dependence with the maintenance of individual institutional autonomy. Faculty adhere to the conventions and expectations (both in terms of promotion and rewards, as well as in terms of academic freedom) of their home institutions. But sometimes the autonomy that institutions and faculty enjoy in these arrangements does not easily transfer over to the students who are enrolled in these programs, and there are examples of issues that students might face, especially with respect to academic freedom and freedom of expression. The inherent blending of academic cultures begins to unveil challenges for both institutions, and, because of this, there is a constant need for negotiation and transparency as the program grows and changes over time. Although most of these programs remain niche program offerings, when these programs work well, they can conceivably set the stage for further collaborations between the home institutions. However, the challenges associated with the merging of academic and administrative cultures make these programs very difficult to start and operate. As a result, many institutions find it is easier to broaden their global brand not by partnering with another university but, rather, with another nation's government (typically via its Ministry of Education, or a similar office) to set up a satellite campus of its own abroad. We discuss this in the next section.

\subsection{Global Satellite or Branch Campuses}

Because it is so challenging to collaborate with another university, we have seen many US universities choose to partner with governments to set up US branches of their own brand abroad. For the most part, universities set up their own campus and maintain virtually all authority over the hiring of faculty, admissions, and program design and standards. Accreditation typically is subsumed under the umbrella of the institution's original accrediting authority, though there may be regional standards with which the institution must comply as well. Degrees are the domain of the institution and are supposed to be the same quality and status of degree as if the student had matriculated at the home location of the institution.

We have seen the most prominent examples of US institutions setting up campuses in the Middle East, e.g., Carnegie Mellon University, Weill Cornell Medicine, Georgetown University, Northwestern University, and New York University, just to name a few [21]. Several other global universities have begun such arrangements, as well (e.g., Paris-Sorbonne University, Abu Dhabi; the London 
Business School, Dubai Center; and the University of Wollongong in Dubai, for example [22-24]).

Many American universities rushed to open up branches in the Gulf Region, attracted by the combination of oil wealth and the area's strong desire for help in creating a higher education infrastructure [25]. Local government efforts to attract global universities to develop campuses that would benefit local students often included some form of subsidy, either to the arriving universities or to the students who would enroll. These governments, in some cases, set aside land for the development of the branch campuses.

But, as we will discuss shortly, the challenges of a fluctuating petrochemical-based economy, the struggle to maintain healthy enrollments when relying solely on local student generation, and the inevitable culture shock American institutions and their faculty experience abroad, have made many of these campuses difficult to operate. As a result, some are on the brink of collapse. Whereas the go-it-alone mentality that serves to extend one's own university brand abroad limits the degree of co-dependence and bolsters institutional autonomy, the attractions of distributing the risk and sharing in the rewards that come with truly co-branded collaborations are increasingly being explored. It is to this we turn to next.

\subsection{Co-branded Institutions}

We have seen, especially in East Asia, a movement in which US-based institutions partner with a local institution to develop a co-branded university. Some notable examples include Duke Kunshan University, Georgia Tech Tianjin University Shenzhen, Tianjin Julliard School, and Yale-National University Singapore. These projects require the creation of an entirely new infrastructure that combines two academic cultures into one. The proposition is tricky, and few co-branded institutions exist as a result. But the movement is gaining momentum, and we suspect more global universities will attempt such partnerships, particularly in China.

Some of these efforts are focused, bringing together the resources of two global institutions to bear upon a set of specific programs or research priorities, such as Duke Kunshan University [26]. Others, such as the Yale-NUS partnership, are a joint creation of an entirely new campus idea, with the aim of introducing the American definition of the liberal arts concept into that nation's system of higher education [27].

Regardless, the number of co-branded institutions that have successfully launched is much smaller than the list of planned collaborations - many have not gotten farther than concepts on paper. In fact, Chinese regulators have closed more than a fifth of partnerships between local and foreign universities as the Communist party tightens its control over mainland higher education [28, 29]. With this action, China essentially cleared up a backlog, closing down concepts that were merely loose agreements but had little chance of ever materializing as actual partnerships.

Aside from this administrative housekeeping, the long-term viability of those co-branded collaborations that have, in fact, been launched cannot be guaranteed. Part of this has to do with the fact that setting up these collaborations, especially in China, requires a nuanced and deeply sophisticated understanding and appreciation of how to do business in the foreign country. Partnering with a Chinese public university amounts to the same thing as doing business with the Chinese government which, essentially, means doing business with the Communist party itself [30]. One must understand party politics and priorities and have deep connections within the power structure of the party apparatus to effectively work with Chinese institutions.

For non-Chinese universities, getting started in China requires a great deal of preparation, cultural knowledge, and a bevy of consultants and partners with ties to the party. These requirements, alone, are not insurmountable. What can make working in China (and, frankly, even within any other part of the world) challenging is when a partner university fails to remember that, when all is said and done, the imperative for the host nation will always be to address its self-defined regional and national priorities. Any global partner that seeks to develop a co-branded institution must not come to the table solely wishing to pursue its own agenda.

\section{Benefits of Global Partnerships}

Given the high costs, complexity, and amount of time needed to establish these types of transnational partnerships, why are US institutions so eager to form them? Their motivations can generally be boiled down to four key reasons: increasing revenues, expanding institutional reputation and brand, globalizing student learning and the impact of scholarship, and expanding access to scholarly opportunities. As depicted in Table 2, however, some motivations are stronger than others for particular types of partnerships. These four factors are detailed further below.

\subsection{Increasing Revenues}

Financial considerations are perhaps the largest driving force behind US institutions seeking partnerships abroad. In recent years, US colleges and universities have witnessed drastic declines in government funding, state support decreasing 40\% between 1980 and 2011 [31]. Because state 
Table 2 Benefits of international partnerships, by type

\begin{tabular}{|c|c|c|c|c|}
\hline International partnerships & $\begin{array}{l}\text { Increasing } \\
\text { revenue }\end{array}$ & $\begin{array}{l}\text { Expanding } \\
\text { brand }\end{array}$ & $\begin{array}{l}\text { Globalizing } \\
\text { learning }\end{array}$ & $\begin{array}{l}\text { Accessing } \\
\text { scholarly } \\
\text { opportunities }\end{array}$ \\
\hline One-on-one collaboration & Low & Low & Low & Medium \\
\hline $\begin{array}{l}\text { Center collaborations and } \\
\text { inter-institution simultaneous } \\
\text { matriculation }\end{array}$ & Low & Medium & Medium & High \\
\hline Joint or dual degree programs & Medium & High & High & High \\
\hline Satellite or branch campuses & High & High & High & High \\
\hline Co-branded institutions & High & High & High & High \\
\hline
\end{tabular}

appropriations have historically represented a large percentage of the annual operating budgets at public institutions, these colleges and universities have become increasingly cash-strapped and thus eager to explore new funding avenues [32].

For institutions seeking to generate significant revenue from global partnerships, branch campuses and co-branded institutions are the most lucrative options on account of the tuition money they generate. In fact, the University of Arizona noted that a primary reason for opening its 25 "microcampuses" across Asia, the Middle East, and Mexico was the potential revenue raised from student tuition [33]. While some joint degree programs may also increase institutional revenues, one-on-one collaborations and concurrent degree programs are not designed to do so.

Beyond tuition dollars, financial incentives offered directly by host countries are also a major pull factor to engage in these global partnerships, particularly for institutions seeking to establish a branch campus or co-branded university. A 2012 report found that $30 \%$ of branch campuses received some type of financial support from the host country. Support can take the form of tax breaks, rent-free facilities, or discounted leases on land [34]. For example, the UAE gifted New York University \$50 million in 2013 to establish its branch campus in Abu Dhabi [35].

\subsection{Expanding Institutional Brand and Reputation}

Internationalization is also a means of strengthening and expanding an institution's brand and overall prestige. US colleges and universities increasingly consider being "world class" as key to their survival in a competitive and interconnected higher education marketplace [2]. This expansion of brand and reputation is a strong motivating factor for establishing joint degree programs, branch campuses, and co-branded universities specifically. This motivation is especially reflected in the marketing materials for such partnerships. For example, Yale-NUS notes that the co-branded college is designed to "educate citizens of the world," aiming "to spur innovation in higher education across the globe" [36]. Similarly, NYU Abu Dhabi has declared itself the "World's Honor College" [37]. These international programs not only generate positive publicity for the US institutions but also are a marker of prestige [38, 39].

In addition, global partnerships enable US institutions to achieve their reputational goals as well as better carry out their missions. For example, Berklee College of Music was drawn to form a branch campus in Valencia, Spain due to the city's strong music history and traditions, bolstering the college's resources for studying flamenco music in particular [40].

\subsection{Globalizing Learning and Impact}

Another commonly cited reason for establishing transnational education partnerships is the potential to expand the learning of students as well as the impact of faculty research. Overseas branch campuses enable US students to more easily study abroad and also support the dissemination of faculty research outside the US context [41]. Likewise, bilateral linkage programs and co-branded institutions can spur development of new curriculum or degree programs that incorporate scholarship and pedagogical techniques from the host country [42]. Connections between US faculty and their counterparts abroad can also inspire curricular and teaching development [43].

Perhaps even more important is that international partnerships assist US institutions in recruiting top students and faculty [44]. For example, one of the motivations for Duke University to open Duke Kunshan University (DKU) was to increase the diversity of its student body as well as its faculty. In 2014 , only $8 \%$ of undergraduates and $23 \%$ of the graduate student population at Duke identified as international [45]. Through the establishment of DKU, Duke has been able to attract more students, as well as faculty members, from overseas. 
Table 3 Challenges of international partnerships, by type

\begin{tabular}{l|l|l|l|l}
\hline International Partnerships & $\begin{array}{l}\text { Risk to } \\
\text { brand }\end{array}$ & $\begin{array}{l}\text { Revenue and enrollment } \\
\text { expectations }\end{array}$ & $\begin{array}{l}\text { Control over } \\
\text { quality }\end{array}$ & $\begin{array}{l}\text { Threats to } \\
\text { autonomy }\end{array}$ \\
\hline One-on-one collaboration & Low & Low & High & Low \\
\hline $\begin{array}{l}\text { Center collaborations and inter-institution simultaneous } \\
\text { matriculation }\end{array}$ & Medium & Medium & Medium & Medium \\
\hline Joint or dual degree programs & Medium & Medium & Medium & High \\
\hline Satellite or branch campuses & High & High & High & High \\
\hline Co-branded institutions & High & High & Medium & High
\end{tabular}

\subsection{Accessing Scholarly Opportunities}

Finally, all types of international partnerships bolster the research of US faculty through the collaboration and funding opportunities they offer. The Singapore-MIT Alliance (SMA) is one example of a transnational partnership that has strengthened the research capabilities and scholarly development of US-based faculty. Established in 1997, SMA was a research enterprise between the Massachusetts Institute of Technology, the National University of Singapore (NUS), and the Nanyang Technology University (NTU) focused on engineering and the life sciences. SMA supported interdisciplinary curriculum development and research within MIT, led to the publication of hundreds of journal articles by MIT and Singaporean researchers, and provided over \$30 million in research money to MIT faculty [46]. Today, the venture still exists in the form of the Singapore-MIT Alliance for Research and Technology (SMART), a collaboration between MIT and the National Research Foundation of Singapore.

The Tsinghua-Berkeley Shenzhen Institute, a partnership between Tsinghua University in China and UC Berkeley, is another example of a successful research alliance. The venture was entirely financed by the Shenzhen municipal government and the Tsinghua Education Foundation, the former contributing $\$ 52$ million toward the creation of buildings and laboratories and the latter investing \$22 million to support student scholarships as well as faculty research in a range of areas including information technology and pharmaceuticals [46]. These international collaborations in many cases can open doors to funding and research opportunities that are otherwise not available domestically.

\section{Challenges of Global Partnerships}

Our analysis of recent articles written about existing global partnerships suggests that there are four major challenges that are raised consistently. These include: risk aversion and its impact on innovation; lower than expected enrollments and revenue; the perceived erosion of, or lack of control over, quality; and threats to autonomy and academic freedom. We will discuss each below. Table 3 summarizes the challenges - risk to brand, risk to revenue/enrollment, threats to quality, and threats to autonomy and academic freedom - presented by each of the types of partnerships.

\subsection{Risk Aversion and Its Impact on Innovation}

Both institutions or parties in any global collaboration must think about the impact the partnership, even if informal in nature, has on their individual brands. Typically, partnerships are in part driven by the promise that it will augment each party's individual brand globally. Though this makes sense from a market-oriented perspective, institutions tend to be risk-averse, only partnering with other institutions that they perceive to be on equal status (or, better yet, even higher status) than themselves. As a result, institutions that initially lack cachet are rarely sought as partners; more often than not, this prevents institutions from seeking potentially high impact partners whose work is transformational, despite their lesser known brand. Places like Harvard University receive hundreds of requests for partnerships, even when those partnerships make little sense. Sadly, another lesser known university might be a much better match for a potential partnership, which could truly be innovative in nature. This phenomenon also impacts higher education's collective capacity to improve opportunity in developing nations. For example, outside of medicine, collaboration between elite research-based institutions and poor nations is lacking [47]. Risk aversion and the protection of (and related desire to improve, by association) institutional brand slow down innovation and out-of-the-box thinking in the global partnership space.

\subsection{Lower Than Expected Enrollment and Revenue}

Among the many partnerships that have begun, the reality of lower than forecasted enrollments and reductions in spending on research by host governments pushes these 
collaborations to the brink of failure. For example, there exist many once-heralded collaborations in the Middle East that are on the precipice of bankruptcy. This has to do, in part, with the economy in this region being so volatile because of its lack of diversification (in a petrochemical-based economy, the fluctuating price of oil puts a dent in consumer and government spending). This volatility directly impacts local students' willingness to enroll, as government subsidies can decrease. For many US-based institutions that set up shop in the Middle East, reliance on local or regional student enrollment has put their operations at risk. Only those institutions (NYU Abu Dhabi, as one example) that have branded their Middle East campuses as enrollment options for students from any part of the world seem to be doing somewhat better. The challenge of enrollment and research support maintenance, minimally speaking, is not insignificant. Growing enrollments and research investments remains an even greater challenge.

\subsection{Perceived Erosion, Lack of Control Over Quality}

Once a partnership is cemented, the question of who controls quality is always evolving. Depending on how the partnership is structured, it can sometimes be difficult to determine who should define academic standards for a program, oversee the hiring and evaluation of faculty, and establish the articulation and assessment of learning goals for students. Local accreditation authorities might have different standards than what the other partner finds familiar, and these different standards may have little to do with academics and everything to do with local imperatives and national economic goals - both of which are subject to shifting political priorities. The challenges here are characterized by a perceived lack of control [48]. That is, the two partner institutions may have little control over the institutionally specific and nationally specific vagaries of policy and politics, all of which invariably bleed over into the higher education space. Sometimes, partners from one national context perceive the other national context to be invested in items associated with efficiency and scale, rather than rigor and quality. The time and energy required to negotiate this landscape can exhaust faculty, leading to lower levels of commitment-a threat to any partnership's survival.

\subsection{Threats to Autonomy and Academic Freedom}

One of the most commonly cited challenges among global partnerships has to do with negotiating different definitions of autonomy and academic freedom. In the US context, both are prized by academics. Institutions enjoy a great deal of autonomy, especially from obtrusive government interference. And individual academics enjoy, in principle, academic freedom. Both of these can be hard to come by in national contexts where, culturally, conceptions of who controls the academic enterprise, and what constitutes acceptable faculty work, are differently understood. US-based faculty working abroad find that they cannot teach as they would in the USA, at least not without a great deal of scrutiny. Government policies as well as disagreements over hot political issues or curricula that run against the grain of local sensibilities and cultural norms [49] can strain expatriate faculty teaching or conducting research abroad, making daily life uncomfortable and, sometimes, even unbearable. When a faculty member lacks the basic freedoms to engage in their work the way they would take for granted in their home nation, the global partnership risks losing the best faculty. No amount of monetary incentives (many of these arrangements make allowances for higher pay, subsidized housing, and so forth) can ever make up for faculty who feel disenfranchised. Collaborations that fail to tackle, and carefully manage, the issues of autonomy and academic freedom are at risk of long-term failure.

\section{Implications and Recommendations}

Global partnerships can be exciting, new ventures that yield innovative programs and research for both partner institutions. But any institution that desires a collaboration with another global partner should balance the benefits with a careful analysis, and detailed plan, to address the inevitable challenges that will arise.

As we suggest in this chapter, global partnerships can take many forms - we have illuminated five, in order of increasing co-dependence and shared autonomy. We recommend that institutions, in the beginning, identify and engage in lower-commitment (what we call "proofof-concept") partnerships, carefully addressing issues that arise and documenting successes. Because so much of the success of partnerships hinges upon trusting relationships, these proof-of-concept arrangements not only serve to build the necessary person-to-person networks needed to manage more complex collaborations, but also stimulate the kind of innovative thinking that yields more ambitious collaborations down the road. In the end, the best partnerships emerge from solid person-to-person relationships that have been forged through working together, managing complexities, and developing a sense of mutual interest and destiny.

We also recommend that any potential global partners take seriously the cultural differences inherent in bringing two institutions from different nations together. Careful negotiation of autonomy, quality determinations, 
accreditation, academic freedom, and assessment or evaluation of outcomes should occur prior to any formal agreements. These issues should not be ignored - hoping they will manage themselves in situ is a fool's errand. We recommend that potential partners have concrete conversations that lead to the clear identification of potential areas of conflict, and a mutually agreeable method for addressing conflicts when they arise. We also recommend that the parameters for faculty work are clearly articulated, and that expatriate faculty members are given clear descriptions of these parameters so they know what to expect.

We recommend that global partnerships deal with money and resources upfront, and in the most transparent fashion possible. These partnerships should carefully forecast revenues and expenditures and stipulate how shortfalls will be managed (as well as attribute responsibilities for any shortfalls say, for example, if government priorities and investment suddenly shift). The development and ongoing management of the physical plant and any cost-sharing agreements should also be agreed upon in advance.

Relatedly, there should be clear agreements regarding the use of brand, name, and trademark, as well as the ownership of any and all intellectual property. Indeed, branding is not a trivial issue, and global partners should carefully consider how a student graduating from a collaborative program will present their credentials. Partnering institutions should think through, carefully, the implications of branding for any concurrent or joint degree programs. And co-branded institutions should consider what they can do to ensure the value of their degrees rises, in the mind of its graduates and the market overall, to the level the degrees offered by the constituent partner institutions.

Finally, we recommend that any potential partnership be driven by values that exceed the mere desire to raise institutional profile, or to increase revenues and market share. Impact matters, and we believe that the collaborations that will stand the test of time, though heeding the importance of revenue generation, are driven by the desire to be truly innovative and to engage real-world challenges. We believe the opportunity to do great work, in the name both of increasing educational access and opportunity and advancing research, exist in regions of the world that have largely been ignored by elite institutions. We also believe that partnerships between institutions that are not among the typical elite can, and will, thrive in the future as these are institutions that are less risk-averse (at least when it comes to protecting brand), and are more open to try new and innovative ventures.

Mostly, we are eager to remind institutions, in their quest to go global, to resist the impulse to think only of their own priorities and immediate needs. Partnerships that are built upon a foundation of shared interests and mutual respect and are also transparent and egalitarian in their decision-making processes will be those that not only stand the test of time, but also have the greatest positive impact.

\section{References}

1. Haynie, D. (2018, January 23). The great game for international students. U.S. News \& World Report. https://www.usnews.com/ news/best-countries/articles/2018-01-23/competition-for-internati onal-students-increases-among-countries. Accessed December 17, 2018.

2. Stanfield, D. A. (2014). International branch campuses: Motivation, strategy, structure (Ph.D. dissertation). Boston College.

3. Leland, D., \& Moore, J. (2007, September/October). Strategic. Public Purpose. http://www.aascu.org/uploadedFiles/AASCU/ Content/Root/MediaAndPublications/PublicPurposeMagazines/ Issue/sep-oct07strategic.pdf. Accessed December 17, 2018.

4. Pietsch, T. (2017). The 1880s: Global connections and the British settler universities. In A. R. Nelson \& N. M. Strohl (Eds.), Universities 2030: Learning from past to anticipate the future (pp. 12-14). Leeds, UK: Worldwide Universities Network.

5. Altbach, P. G. (2004). Globalization and the university: Myths and realities in an unequal world. Tertiary Education and Management, 10(1), 3-25. https://doi.org/10.1080/13583883.2004. 9967114.

6. Ashby, E. (1964). Universities: British, Indian, Africa. Cambridge, MA: Harvard University Press.

7. Wang, D. (2007). Managing god's higher learning: US-China cultural encounter and Canton Christian College (Lingnan University), 1888-1952. Lanham, MD: Lexington Books.

8. Lanford, M., \& Tierney, W. G. (2016). The international branch campus: Cloistered community or agent of social change? In C. S. Collins, M. N. Lee, J. N. Hawkins, \& D. E. Neubauer (Eds.), The Palgrave handbook of Asia Pacific higher education (pp. 157172). New York: Palgrave Macmillan.

9. Contreras, E., Jr. (2015). Beyond the grand tour: Re-thinking the education abroad narrative for US higher education in the 1920s. International Journal of Tourism Anthropology, 4(3), 238-251. https://doi.org/10.1504/IJTA.2015.071931.

10. Comp, D. (2016). A historical overview of international education scholarship and the role of the scholar-practitioner. In B. Streitwieser \& A. C. Ogden (Eds.), International higher education's scholar-practitioners: Bridging research and practice (pp. 73-92). Oxford: Symposium Books Ltd.

11. Walton, W. (2005). Internationalism and the junior year abroad: American students in France in the 1920s and 1930s. Diplomatic History, 29(2), 255-278. https://doi.org/10.1111/j.1467-7709. 2005.00473.x.

12. Healy, N. (2014). When is an international branch campus? International Higher Education, 78(1), 22-23. https://doi.org/10. 6017/ihe.2014.78.5808.

13. The New School, About Parsons Paris-History. https://www. newschool.edu/parsons-paris/history/. Accessed December 17, 2018.

14. Guttenplan, D. D. (2012, November 11). Parsons to re-open campus in Paris. New York Times. https://www.nytimes.com/2012/ 11/12/world/europe/12iht-educside12.html. Accessed December 17,2018 
15. Becker, R. (2009). International branch campuses: Markets and strategies. London: The Observatory on Borderless Higher Education.

16. Chambers, G., \& Cummings, W. (1990). Profiting from education: Japan-United States international educational ventures in the 1980s. New York: Institute of International Education.

17. Knight, J. (2011). Education hubs: A fad, a brand, an innovation. Journal of Studies in International Education, 15(3), 221-240. https://doi.org/10.1177/1028315311398046.

18. Garrett, R., Kinser, K., Lane, J. E., \& Merola, R. (2016). International branch campuses-Trends and developments 2016. Surrey, UK: OBHE \& C-BERT.

19. Altbach, P. G. (2007). Twinning and branch campuses: The professorial obstacle. International Higher Education, 48(1), 2-3. https://ejournals.bc.edu/ojs/index.php/ihe/article/view/7976/7127.

20. Crist, J. T. (2017). U.S. universities and international branch campuses. IEM Spotlight Newsletter, 14(1). https://www.nafsa.org/ Professional_Resources/Browse_by_Interest/International_ Students_and_Scholars/Network_Resources/International_ Enrollment_Management/U_S_Universities_and_International_ Branch Campuses/.

21. New York University Abu Dhabi. Vision and mission. https:// nyuad.nyu.edu/en/about/nyuad-at-a-glance/vision-and-mission. html. Accessed February 15, 2019.

22. Paris-Sorbonne University Abu Dhabi. About us. https://www sorbonne.ae/about-us/. Accessed February 15, 2019.

23. London Business School Dubai Center, Dubai. https://www. london.edu/about/location/dubai. Accessed February 15, 2019.

24. University of Wollongong in Dubai. Overview. https://www. uowdubai.ac.ae/about-uowd/overview. Accessed February 15, 2019.

25. Lewin, T. (2009, December 27). University branches in Dubai are struggling. New York Times. https://www.nytimes.com/2009/12/ 28/education/28dubai.html. Accessed December 17, 2018.

26. Redden, E. (2018, April 4). An Ivy degree, with an Irish twist. Inside Higher Education. https://www.insidehighered.com/news/ 2018/04/04/columbia-trinity-college-dublin-start-new-dual-baprogram. Accessed December 17, 2018.

27. Prihar, A., \& Cho, S. (2018, November 8). Yale, Yale-NUS look to strengthen partnership. Yale Daily News. https://yaledailynews. com/blog/2018/11/08/yale-yale-nus-look-to-strengthenpartnership/. Accessed December 17, 2018.

28. Feng, E. (2018, July 17). China closes a fifth of foreign university partnerships. Financial Times. https://www.ft.com/content/ 794b77e8-8976-11e8-bf9e-8771d5404543. Accessed December 17, 2018.

29. Redden, E. (2018, July 11). Closures of China-foreign programs. Inside Higher Education. https://www.insidehighered.com/news/ 2018/07/11/chinas-ministry-education-approves-terminationmore-200-chinese-foreign-cooperative. Accessed December 17, 2018.

30. Kirby, W. C. (2014). The Chinese century? The challenges of higher education. Daedalus, 143(2), 145-156. https://doi.org/10. 1162/DAED_a_00279.

31. Mortenson, T. (2012, Winter). State funding: A race to the bottom. American Council on Education. https://www.acenet.edu/thepresidency/columns-and-features/Pages/state-funding-a-race-tothe-bottom.aspx. Accessed December 17, 2018.

32. Mitchell, M., Leachman, M., \& Masterson, K. (2017, August 27). A lost decade in higher education funding. Center on Budget and
Policy Priorities. https://www.cbpp.org/research/state-budget-andtax/a-lost-decade-in-higher-education-funding. Accessed December 17, 2018.

33. Redden, E. (2017, May 23). Going big into 'microcampuses.' Inside Higher Education. https://www.insidehighered.com/news/ 2017/05/23/arizona-embarks-plan-develop-25-globalmicrocampuses. Accessed December 17, 2018.

34. Varghese, N. V. (2017). Globalization and cross-border mobility in higher education. In T. R. Dash \& M. Behera (Eds.), Educational access and excellence (pp. 9-24). New Delhi: Allied Publishers Pvt. Ltd.

35. Redden, E. (2013, March 11). Global ambitions. Inside Higher Education. https://www.insidehighered.com/news/2013/03/11/nyuestablishes-campuses-and-sites-around-globe. Accessed December 17, 2018.

36. Yale-NUS College. Vision and mission. https://www.yale-nus.edu. sg/about/vision-and-mission/. Accessed December 17, 2018.

37. Redden, E. (2010, June 21). The world's honors college? Inside Higher Education. https://www.insidehighered.com/news/2010/ 06/21/worlds-honors-college. Accessed December 17, 2018.

38. Slaughter, S., \& Leslie, L. L. (1997). Academic capitalism: Politics, policies, and the entrepreneurial university. Baltimore: Johns Hopkins University Press.

39. Verbik, L., \& Merkley, C. (2006). The international branch campus: Models and trends. London: The Observatory on Borderless Higher Education.

40. Fuchs, D. (2012, September 17). Berklee College of music opens campus in Spain. Boston Globe. https://www.bostonglobe.com/ arts/music/2012/09/17/berklee-college-music-opens-new-valenciacampus/ptE7agZxA7EuVZzyjDrZvN/story.html. Accessed December 17, 2018.

41. Lane, J. E., \& Kinser, K. (2011). Reconsidering privatization in cross-border engagements: The sometimes public nature of private activity. Higher Education Policy, 24(2), 255-273. https://doi.org/ 10.1057/hep.2011.2.

42. Shams, F., \& Huisman, J. (2012). Managing offshore branch campuses: An analytical framework for institutional strategies. Journal of Studies in International Education, 16(2), 106-127. https://doi.org/10.1177/1028315311413470.

43. Clifford, M. (2015). Assessing the feasibility of international branch campuses: Factors universities consider when establishing campuses abroad (Ph.D. dissertation). Pardee RAND Graduate School.

44. Edelstein, R. J., \& Douglass, J. A. (2012). Comprehending the international initiatives of universities: A taxonomy of modes of engagement and institutional logics. Research \& Occasional Paper Series: CSHE.19.12. Berkeley, CA: UC Berkeley.

45. Huang, C. (2014, October 15). Duke Kunshan University-A bold innovation. Sanford Journal of Public Policy. https://webcache. googleusercontent.com/search?q=cache:E0ncwQN7GBMJ:https://si tes.duke.edu/sjpp/2014/duke-kunshan-university-a-bold-innovation/+ $\& c d=6 \& h \mathrm{l}=\mathrm{en} \& \mathrm{ct}=\mathrm{clnk} \& \mathrm{gl}=\mathrm{us}$. Accessed December 17, 2018.

46. Youtie, J., Li, Y., Rogers, J., \& Shapira, P. (2017). Institutionalization of international university research ventures. Research Policy, 46(9), 1692-1705. https://doi.org/10.1016/j.respol.2017. 08.006 .

47. Baker, S. (2018, September 21). Ignoring developing countries. Inside Higher Education. https://www.insidehighered.com/news/ 
2018/09/21/study-finds-limited-collaboration-between-researchelites-and-developing-nations. Accessed December 17, 2018.

48. Lane, J. E. (2011). Global expansion of international branch campuses: Managerial and leadership challenges. New Directions for Higher Education, 2011(155), 5-17. https://doi.org/10.1002/ he. 440 .

Open Access This chapter is licensed under the terms of the Creative Commons Attribution 4.0 International License (http:// creativecommons.org/licenses/by/4.0/), which permits use, sharing, adaptation, distribution and reproduction in any medium or format, as long as you give appropriate credit to the original author(s) and the source, provide a link to the Creative Commons license and indicate if changes were made.
49. Redden, E. (2018, October 29). Cutting ties: Cornell university ends a partnership with Renmin University of China, citing academic freedom concerns. Inside Higher Education. https://www. insidehighered.com/news/2018/10/29/cornell-ends-partnership-chi nese-university-over-academic-freedom-concerns. Accessed Dece mber 17, 2018.
The images or other third party material in this chapter are included in the chapter's Creative Commons license, unless indicated otherwise in a credit line to the material. If material is not included in the chapter's Creative Commons license and your intended use is not permitted by statutory regulation or exceeds the permitted use, you will need to obtain permission directly from the copyright holder. 